\title{
From chemical shift data through prediction to assignment and NMR LIMS - multiple functionalities of nmrshiftdb2
}

\author{
Stefan Kuhn ${ }^{1 *}$, Nils E Schlörer ${ }^{2}$, Heinz Kolshorn ${ }^{3}$, Raphael Stoll ${ }^{4}$ \\ From 7th German Conference on Chemoinformatics: 25 CIC-Workshop \\ Goslar, Germany. 6-8 November 2011
}

nmrshiftdb2 and its predecessor NMRShiftDB [1,2] have been available as a community-based NMR database since 2002. During that time a continuously growing set of currently more than 40000 structures with 48600 spectra could be established. These data are freely available (http://nmrshiftdb.org) and cannot only be searched but can also be downloaded and used for scientific investigations. Supplementary to the database, supplementary software was developed including an NMR lab administration system.

Recently, there were some changes in the team and we had a rebranding to nmrshiftdb2. Now, we would be very interested to enter discussion about the project and its future perspectives by receiving feedback from former, current and potential users of different areas. We will discuss the state of this project, e.g. software functions, data collection, and use for research.

An important new feature is the laboratory information management system (LIMS) which has been developed with the intention to better integrate the database functionality into an academic NMR laboratory environment. Nmrshiftdb2 now allows NMR laboratories at the same time to administer and account for their users, instruments and measurements and use the known database functions from the same surface.

\section{Author details}

'Aureliusstr. 45, 52067 Aachen, Germany. ${ }^{2}$ Department of Chemistry,

University of Cologne, 50939 Köln, Germany. Institut für Organische Chemie, Johannes-Gutenberg-Universität, 55128 Mainz, Germany. ${ }^{4}$ Biomolecular NMR, Ruhr-Universität Bochum, Bochum, Germany.

\section{Published: 1 May 2012}

\footnotetext{
* Correspondence: stefhk3@web.de

'Aureliusstr. 45, 52067 Aachen, Germany

Full list of author information is available at the end of the article
}

\section{References}

1. Steinbeck C, Kuhn S: NMRShiftDBConstructing a Free Chemical Information System with Open-Source Components. Phytochemistry 2004, 65:2711-2717.

2. Steinbeck C, Krause S, Kuhn S: NMRShiftDB - compound identification and structure elucidation support through a free community-built web database. J Chem Inf Comput Sci 2003, 43:1733-1739.

\section{doi:10.1186/1758-2946-4-S1-P52}

Cite this article as: Kuhn et al:: From chemical shift data through prediction to assignment and NMR LIMS - multiple functionalities of nmrshiftdb2. Journal of Cheminformatics 2012 4(Suppl 1):P52.

\section{Publish with ChemistryCentral and every scientist can read your work free of charge \\ "Open access provides opportunities to our colleagues in other parts of the globe, by allowing anyone to view the content free of charge." \\ W. Jeffery Hurst, The Hershey Company. \\ - available free of charge to the entire scientific community \\ - peer reviewed and published immediately upon acceptance \\ - cited in PubMed and archived on PubMed Central \\ - yours - you keep the copyright \\ Submit your manuscript here: \\ http://www.chemistrycentral.com/manuscript/

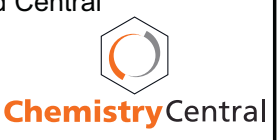

